\title{
Successful Treatment and Management of Canine Ehrlichiosis-Leishmaniosis-Heartworm Comorbidity
}

\author{
Adam Leal-Lima ${ }_{\odot}{ }^{1}$, Tiago Cunha Ferreira ${ }^{1}$, Társsila Mara Vieira Ferreira ${ }^{1}$, \\ Pedro Covas Coelho² \& Diana Célia Sousa Nunes-Pinheiro ${ }^{1}$
}

\begin{abstract}
Background: Canine vector borne diseases (CVBD) are common in tropical countries where the climate favors arthropods abundance. Comorbidity with one or more CVBD are reported as clinical complication and worsen prognostic. Canine visceral leishmaniosis (CanL) is an endemic zoonotic disease in Brazil caused by Leishmania infantum, with several restrictions to canine treatment and suggestion of reservoirs euthanasia for disease control. Heartworm (HW) is a helminthic disease caused by Dirofilaria immitis infection in dogs. It is a chronic heart disease, which can lead to death by congestive heart failure. Canine ehrlichiosis (CE) is caused by Ehrlichia canis bacterial infection with a zoonotic potential and fatal to dogs in acute and chronic presentations. Exposed the above, this study aims to describe a successful treatment and management of a dog with CanL, CE, and HW comorbidity.

Case: A 3-year-old male uncastrated black Labrador dog, weighing $35 \mathrm{~kg}$, was admitted to the veterinary clinic due to immunochromatographic CanL positive test performed by municipal zoonosis control center active surveillance. Clinical exam showed a mild shedding, intermittent eye white/yellow discharge and popliteal lymph nodes enlargement. After positive for CanL, veterinary requested more laboratorial exams. IFAT and ELISA were positive for CanL, blood smear showed presence of microfilaria, and bone marrow cytology showed Ehrlichia spp. morulae and microfilaria. Initial treatment prescribed was oral doxycycline, omeprazole, ranitidine, and domperidone for 30 days, and allopurinol and ivermectin until further recommendation. Additionally, repellent collar, repellent spray and vitamin supplement was indicated. After first month, marbofloxacin for 30 days and three doses of immunostimulant drug were administrated. After three months of treatment, dog still positive for heartworm, ehrlichiosis, and CanL. Doxycycline protocol was repeated. Dog became consistently negative for all pathogens one year later with persistent thrombocytopenia but without clinical signs, ergo allopurinol and ivermectin were discontinued. After 4 years of follow up, the animal had an acute pancreatitis and died, with unremarkable total blood count and negative for all pathogens.

Discussion: CVBD coinfections are commonly reported as worsen prognostic in endemic regions. The pathogens reported here share a host immunomodulation competence. L. infantum and Ehrlichia spp. downregulates Th1 response, whereas D. immitis increase as Th2 profile. The therapeutic protocol was iniciated by staging CanL. Since the patient had clinical signs, allopurinol was prescribed as a well-established drug for CanL. Marbofloxacin was added due to its high safety drug in clinical improvement of infected dogs with and without renal disease and in vitro effectiveness against $L$. infantum. Domperidone was used to promote Th1 cytokine profile as INF- $\gamma$, IL-2, IL-12, and TNF- $\alpha$. We used an immunostimulant protocol to favor polarization to the Th1 profile comprised by 30 days of domperidone protocol followed by a vaccine and an immunomodulator. Doxycycline was used successfully for Ehrlichia spp. and HE clearance after 2 treatment courses and 1 year of ivermectin every 15 days. The animal presented intermittent coughing episodes on the first treatment course, but no medical intervention was needed besides exercise restriction. Our report shows the successful management of one dog with CanL, CE and HE comorbidity. This success was possible due to early detection and good therapeutic choice.
\end{abstract}

Keywords: canine visceral leishmaniosis, coinfection, Dirofilaria immitis, Erhlichia canis, Leishmania infantum, treatment. 
A. Leal-Lima, T.C. Ferreira, T.M.V. Ferreira, P.C. Coelho \& D.C.S. Nunes-Pinheiro. 2021. Successful Treatment and Management of Canine Ehrlichiosis-Leishmaniosis-Heartworm Comorbidity. Acta Scientiae Veterinariae. 49(Suppl 1): 687.

\section{INTRODUCTION}

Canine visceral leishmaniosis (CanL), ehrlichiosis (CE) and heartworm (HW) are examples of canine vector-borne diseases (CVBD) endemic in Brazil $[4,13,27]$. Comorbidity is related to worsen prognosis, thus early diagnostic is crucial to avoid critical illness [2,31].

Dogs with CanL or CE can be apparently healthy or present a broad of alterations including dermatitis, emesis, lymph nodes enlargement, and conjunctivitis. They are caused by Leishmania infantum and Ehrlichia canis infection, transmitted by Lutzomiya longipalpis sandfly and by Rhipicephalus sanguineus tick respectively $[18,28]$.

Treatment of CanL needs assorting stage accordingly, since animals in early stages have good prognosis [6,28]. Additionally, dogs without clinical signs are related to lower transmission of the parasite to the vector [15]. Doxycycline is recommended to treat $\mathrm{CE}$, it is efficient in clinical signs remission but can be repeated to clear infection [18,34].

Canine HW is caused by Dirofilaria immitis nematodes and transmitted by mosquito species, including Aedis, Anopheles, and Culex [9,29]. The adult worms parasitize pulmonary arteries and right heart chambers. Disease presentation will depend on parasite load, normally dogs remain without clinical signs with detectable microfilaria on blood smear, but cough and exercise intolerance can be observed [5]. Alternative slow killing treatment with macrocyclic lactone and doxycycline are reported $[3,16]$.
These 3 CVBD cited can have silent infection or severe chronic diseases presentation. Therefore, the aim of this case report is to describe a successful treatment and management of a dog with CanL, CE, and HW comorbidity.

\section{CASE}

A 3-year-old male uncastrated black Labrador dog, weighing $35 \mathrm{~kg}$, was admitted to the veterinary clinic due to immunochromatographic CanL positive test $^{1}$ (Dual Path Plataform ${ }^{\circledR}$ ) performed by municipal zoonosis control center active surveillance in August 2014. Thereafter, dog was positive for CanL on IFAT (1:80), and ELISA, and for Ehrlichia spp. morulae and microfilaria on bone marrow cytology. Clinical exam showed a mild hair loss, popliteal lymph nodes enlargement, hyperemia mucous membranes, and intermittent eye discharge. Nonetheless the animal was active, normal temperature, and appetite. Total blood count, sera levels of creatinine, urea, and alanine aminotransferase were unremarkable, but microfilaria was observed on blood smear (Table 1 and Table 2).

An Ehrlichia spp. infection was reported one year before (2013), but no confirmatory diagnostic was done previously or after treatment. At the time, emesis, lack of appetites, alopecia, lymph node enlargement, and fever were detected on clinical exam. Dog was treated with intramuscular tetracycline injections for 21 days. Diagnostic and clinical management was done monitoring clinical improvement, platelet morphology and count (Table 1). Treatment was finished and the dog was healthy until August 2014.

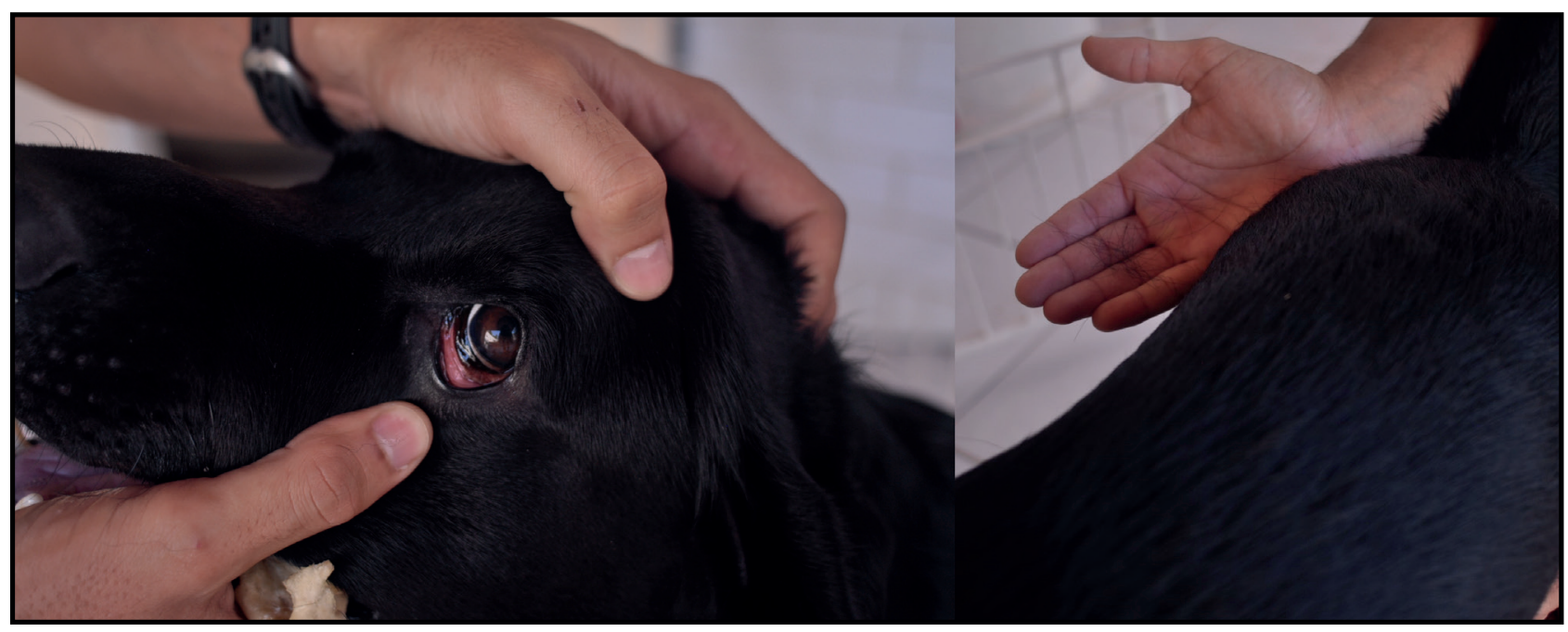

Figure 1. Picture of the dog in August 2014 showing hyperemic mucous membranes and mild alopecia. 
A. Leal-Lima, T.C. Ferreira, T.M.V. Ferreira, P.C. Coelho \& D.C.S. Nunes-Pinheiro. 2021. Successful Treatment and Management of Canine Ehrlichiosis-Leishmaniosis-Heartworm Comorbidity.

Acta Scientiae Veterinariae. 49(Suppl 1): 687.

Table 1. Hematological and serological exams (2013-2018) of a 3-year-old male uncastrated black Labrador dog with leishmaniosis, heartworm, and ehrlichiosis comorbidity.

\section{Period $^{*}$}

\begin{tabular}{|c|c|c|c|c|c|c|c|c|c|c|c|c|c|c|}
\hline Parameter & $\begin{array}{c}\text { Apr } \\
2013\end{array}$ & $\begin{array}{l}\text { May } \\
2013\end{array}$ & $\begin{array}{l}\text { Aug } \\
2014\end{array}$ & $\begin{array}{l}\text { Sep } \\
2014\end{array}$ & $\begin{array}{l}\text { Oct } \\
2014\end{array}$ & $\begin{array}{l}\text { Nov } \\
2014\end{array}$ & $\begin{array}{c}\text { Dez } \\
2014\end{array}$ & $\begin{array}{l}\text { Feb } \\
2015\end{array}$ & $\begin{array}{l}\text { Apr } \\
2015\end{array}$ & $\begin{array}{c}\text { Sep } \\
2015\end{array}$ & $\begin{array}{c}\text { Jan } \\
2016\end{array}$ & $\begin{array}{l}\text { May } \\
2016\end{array}$ & $\begin{array}{l}\text { Oct } \\
2017\end{array}$ & $\begin{array}{c}\text { Sep } \\
2018\end{array}$ \\
\hline $\begin{array}{c}\text { RBC } \\
\left(\mathrm{x} 10^{6} / \mu \mathrm{L}\right)\end{array}$ & 4.42 & 5.09 & 6.05 & 7.02 & 6.08 & 7.04 & 6.53 & 6.08 & 6.02 & 6.67 & 6.46 & 7.72 & 6.91 & 7.72 \\
\hline $\begin{array}{c}\mathrm{Hb} \\
(\mathrm{g} / \mathrm{dL})\end{array}$ & 10 & 13.8 & 15.5 & 16.1 & 13.8 & 16.7 & 15.1 & 14.1 & 13.6 & 15.5 & 15.1 & 17.6 & 16.2 & 19.9 \\
\hline $\begin{array}{l}\text { Hct } \\
(\%)\end{array}$ & 31.1 & 38 & 45.3 & 49.9 & 43 & 50.6 & 45.1 & 43.8 & 39.7 & 47.4 & 45.8 & 52.1 & 46.9 & 52.9 \\
\hline $\begin{array}{c}\text { WBC } \\
\left(\mathrm{x} 10^{3} / \mu \mathrm{L}\right)\end{array}$ & 8.4 & 18.8 & 16.9 & 13.0 & 19.0 & 19.2 & 18.0 & 19.7 & 11.0 & 17.6 & 19.6 & 14.6 & 12.9 & 16.8 \\
\hline $\begin{array}{c}\text { Plt } \\
\left(\times 10^{3} / \mathrm{uL}\right)\end{array}$ & 63 & 128 & 210 & 167 & 196 & 160 & 169 & 108 & 117 & 106 & 163 & 125 & 205 & 576 \\
\hline $\begin{array}{l}\text { Plt } \\
\text { Mor }\end{array}$ & GP & GP & $\mathrm{n}$ & $\mathrm{n}$ & GP & GP & GP & $\mathrm{n}$ & GP & $\mathrm{n}$ & GP & $\mathrm{n}$ & $\mathrm{n}$ & $\mathrm{n}$ \\
\hline $\begin{array}{l}\text { TPP } \\
(\mathrm{g} / \mathrm{L})\end{array}$ & 6.6 & 7.2 & 7 & 7 & 6.8 & 7.2 & 7 & 7.4 & 7.2 & 7.4 & 7.6 & 8 & 8.4 & 14 \\
\hline $\begin{array}{c}\text { Creat. } \\
(\mathrm{mg} / \mathrm{dL})\end{array}$ & - & - & 1.2 & 1.29 & - & 1.02 & - & 1.2 & 0.98 & - & - & 0.86 & - & 1.3 \\
\hline $\begin{array}{c}\text { BUN } \\
(\mathrm{UI} / \mathrm{dL})\end{array}$ & - & - & 50.9 & 49.0 & - & 24.0 & - & - & - & - & - & - & - & 30.0 \\
\hline $\begin{array}{c}\text { ALT } \\
\text { (UI/L) }\end{array}$ & - & 101 & 54 & 56 & - & 55 & - & 88 & 24.1 & - & - & 329 & - & 210 \\
\hline
\end{tabular}

"Treatment started at August 2014. RBC: red blood cells; Hb: hemoglobin; Hct: hematocrit; WBC: White blood cells; Plt: Platelet count; Plt Mor: Platelet morphology; TPP: Total plasma proteins; Creat: serum creatinine; Blood urea nitrogen; ALT: alanine aminotransferase; GP: Giant platelets; n: Normal; -: Non available.

Initial treatment prescribed was oral doxycycline $^{2}$ [Doxitrat ${ }^{\circledR}-10 \mathrm{mg} / \mathrm{kg}, \mathrm{VO}$, SID for 28 days] for HW and CE. Omeprazole ${ }^{3}$ [Medley $^{\circledR}-1 \mathrm{mg} / \mathrm{kg}, \mathrm{VO}$, SID for 35 days] and ranitidine ${ }^{3}$ [Medley ${ }^{\circledR}-2 \mathrm{mg} / \mathrm{kg}$, VO, BID for 30 days] were administrated to avoid gastritis, and ivermectin ${ }^{2}\left[\right.$ Mectimax $^{\circledR}-6 \mu \mathrm{g} / \mathrm{kg}, \mathrm{VO}$, once every 15 days until clearance of $D$. immitis].

No parasitological or laboratorial exams substantiate prescription of leishmanicidal drugs, despite positive in 3 serological tests (Table 2). Therefore, dog was categorized as CanL stage I and therapy was prescribed as follows: domperidone ${ }^{4}\left[\mathrm{EMS}^{\circledR}\right.$ $0.5 \mathrm{mg} / \mathrm{kg}, \mathrm{VO}$, SID for 30 days], allopurinol $^{3}$ [Medley ${ }^{\circledR}$ - $10 \mathrm{mg} / \mathrm{kg}$, VO, SID until further recommendation]. Additionally, repellent collar ${ }^{5}$ (Scalibor $^{\circledR}$ ), repellent $\operatorname{spray}^{6}$ (Karflae Citronela ${ }^{\circledR}$ ), and vitamin supplement ${ }^{7}$
(Glicopan Pet ${ }^{\circledR}$ ) were indicated. Dog showed intermittent emesis and coughs during this first protocol, even with exercise restriction.

After doxycycline and domperidone protocol (30 days of treatment), marbofloxacin ${ }^{8}$ [Marbopet ${ }^{\circledR}$ $3 \mathrm{mg} / \mathrm{kg}$ VO, SID for 30 days], and 3 subcutaneous doses of commercial immunomodulator ${ }^{8}$ [Infervac ${ }^{\circledR}$ - $2 \mathrm{~mL}$ ] plus CanL vaccine ${ }^{8}$ [Leishtec $^{\circledR}-2 \mathrm{~mL}$ ] once every 21 days were administrated. During this period, emesis and coughing episodes decreased.

In November 2014 (72 days of treatment), blood and bone marrow smear were negative for microfilaria (Table 2), but platelet count was lower compared to August 2014 and giant platelets were observed (Table 1). Serological tests for heartworm and CanL were positive, and bone marrow smear revealed 
A. Leal-Lima, T.C. Ferreira, T.M.V. Ferreira, P.C. Coelho \& D.C.S. Nunes-Pinheiro. 2021. Successful Treatment and

Table 2. Parasitological, serological, and molecular tests (2013-2018) of a 3-year-old male uncastrated black Labrador dog (2013-2018) with leishmaniosis, heartworm, and ehrlichiosis comorbidity.

\begin{tabular}{cccccccccccccccc}
\hline \multicolumn{11}{c}{ Period* $^{*}$} \\
\hline Test & Apr & May & Aug & Sep & Oct & Nov & Dez & Feb & Apr & Sep & Jan & May & Oct & Sep \\
& 2013 & 2013 & 2014 & 2014 & 2014 & 2014 & 2014 & 2015 & 2015 & 2015 & 2016 & 2016 & 2017 & 2018 \\
\hline $\begin{array}{c}\text { Blood } \\
\text { Smear }\end{array}$ & n & n & MF & MF & n & n & n & n & n & n & n & n & n & $n$ \\
DPP® & - & - & Pos & - & - & - & - & - & - & - & - & - & - & - \\
Bone & & & E / & & & & & & & & & & & \\
Marrow & - & - & MF & - & - & E & - & N & - & - & - & - & - & - \\
Cyt & & & & & & & & & & & & & & \\
HW S & - & - & - & - & - & Pos & - & Pos & - & N & - & - & - & - \\
IFAT & - & - & $1: 80$ & - & N & $1: 40$ & - & N & N & N & N & N & N & N \\
ELISA & - & - & Pos & - & N & Pos & - & N & N & N & N & N & N & IND \\
PCR & - & - & - & - & - & - & - & - & - & - & - & - & N & N \\
\hline
\end{tabular}

"Treatment started at August 2014. DPP ${ }^{\circledR}$ : Immunochromatographic Dual Path Plataform for Leishmanina infantum; Bone Marrow Cyt: Bone marrow cytology; HW S: Hear worm serological test; IFAT: Immunofluorescence antibody test for Leishmania infantum; ELISA: Enzyme-linked immunosorbent assay for Leishmania infantum; n: Normal; -: Non available; N: Negative; MF: Microfilaria observed; E: Ehrlichia spp. morulae observed; Pos: positive; IND: indeterminate; PCR: Whole blood polymerase chain reaction for Leishmania spp.

Ehrlichia spp. morulae (Table 2). Thus, doxycycline with omeprazole protocol was repeated in a lower dose [7.5 mg/kg, $1 \mathrm{mg} / \mathrm{kg}$ VO, SID for 28 days respectively]. On this second treatment course, dog showed improved exercise tolerance and no emesis. Ivermectin, allopurinol, vitamin supplement, repellent collar, and spray were maintained until September 2015, when serological HW and CanL test were negative (Table 2).

After one year of clinical management, dog became consistently negative for all pathogens with persistent thrombocytopenia (Table 1 and 2). From 2015 until 2018, the patient did not show coughing, eye discharge or emesis, with exercise tolerance, appetite and healthy. In September 2018, dog was admitted to the clinic because of a lack of appetite and emesis. Acute pancreatitis was diagnosed by abdominal ultrasonography causing death of the animal with unremarkable total blood count and negative for all pathogens, including L. infantum whole blood PCR (Table 2).

\section{DISCUSSION}

This study shows a dog that lived for years after CanL, HW, and CE comorbidity remission after treatment according to the literature. These diseases have severe chronical presentations but favorable prognosis in early diagnosis [6,28].
CVBD coinfections are commonly reported as worsen prognostic in endemic regions, where vectors are abundant allowing higher transmission rates [10,31] . The pathogens reported here share a host immunomodulation competence. Leishmania infantum and Ehrlichia spp. downregulate Th1 response and macrophages killing effectiveness, by different pathways, resulting in pathogen intracellular survival and replication [14,32]. Hence, a mammal infected by one organism can be more susceptible to infection with the other. Dirofilaria immitis can immunomodulate the host by increasing Th2 profile which downregulates Th1 response, favoring an infection by intracellular pathogens, such as Ehrlichia spp. and Leishmania spp. [17]. On our report, the order of events cannot be stablished, but certainly these CVBD are favored by climate, vector/pathogen abundance and/or host immunomodulation.

The therapeutic protocol iniciated by staging the CanL which the patient can be classified in 4 or 5 stages. According Leishvet [28] and Brasileish group [6], our patient had good prognosis classified as stage I and stage II, respectively. Recommended treatment ranges from scientific neglect to allopurinol, immunotherapy, immunomodulation, and miltefosine $[6,28]$. Since the patient had clinical signs, allopurinol was prescribed as a well-established drug for CanL. 
Marbofloxacin was added in therapeutic as an alternative drug for CanL due to its high safety drug in clinical improvement of infected dogs with and without renal disease $[22,25]$. Furthermore, in vitro effectiveness against $L$. infantum strains was reported $[1,11]$.

Domperidone was used on recommended lowsecure dose $[0.5 \mathrm{mg} / \mathrm{kg}$, VO, SID, for 30 days] for its results on clinical remission and prevention of CanL. This drug increases prolactin serum level, and this hormone has been related to promote Th1 cytokine profile as INF- $\gamma$, IL-2, IL-12, and TNF- $\alpha$ [26,33]. Immunotherapeutic approaches are reported as efficient on preventing disease progression in CanL stages I and II [30]. These protocols are based on switching Treg or Th2 to a Th1 profile, enhancing parasite clearance $[23,24]$. Here we used an immune stimulant protocol to polarize Th1 patient response comprised by 30 days of domperidone protocol followed by a vaccine with A2 Leishmania antigen conjugated with saponin $\left(\right.$ Leishtec $^{\circledR}$ ), an immunomodulator (Infervac ${ }^{\circledR}$ ), with Escherichia coli lipopolysaccharide and inactivated cells of Propionibacterium acnes. This protocol was repeated annually.

Prognostic of CE and HW is good when detected early and doxycycline is a recommended drug

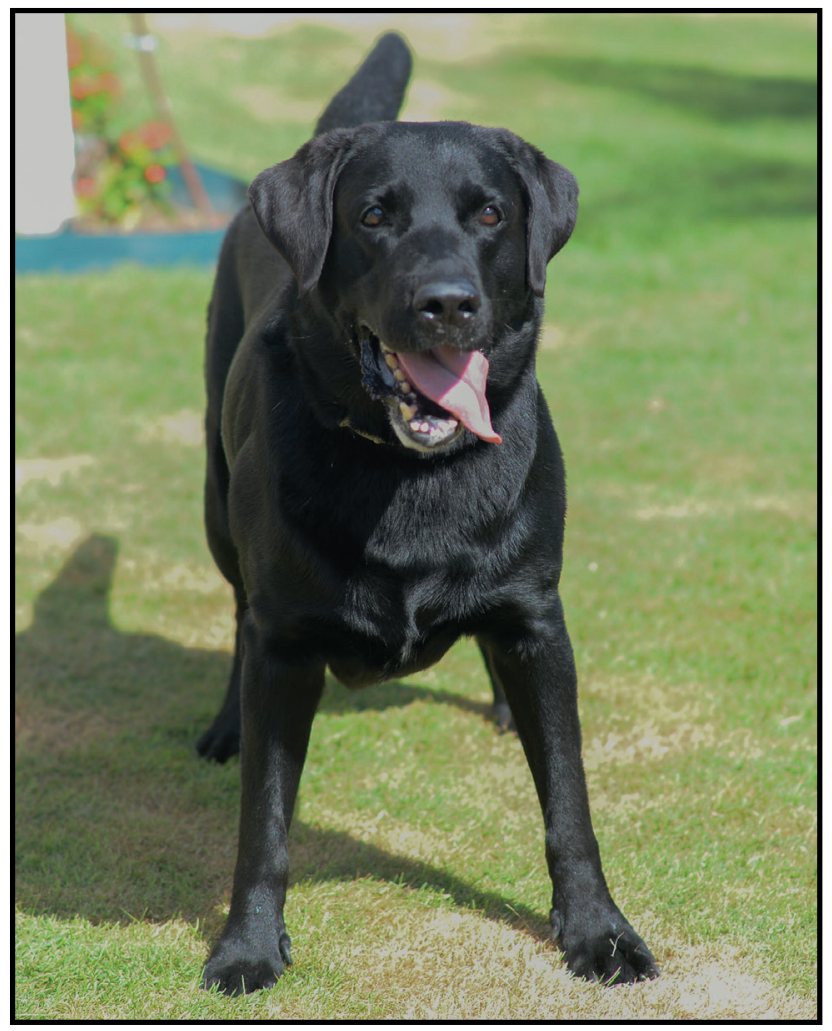

Figure 2. Picture of the dog in December 2017 showing wellness. for $\mathrm{CE}$ and $\mathrm{HW}$, thus was prescribed on the initial treatment. Doxycycline is efficient for CE in clinical improvement but may not clear infection in one treatment course. Hence, repeating the treatment is suggested before using alternative drug since Ehrlichia spp. resistance to tetracycline derivatives was not reported [18]. On our study, prescribed protocol for Ehrlichia spp. did not clear the bacterial infection in one course, therefore it was repeated after two months being successful despite lowering the dose.

A long-term alternative treatment for HW is association of doxycycline with ivermectin [21]. Here we report a patient diagnosed with $D$. immitis by visualization of microfilaria on blood smear (Table 2). Echodopplercardiography was done in September 2014, but no adult worms were visualized. The alternative treatment chosen suggests ivermectin continuous use until seroconversion, since microfilaremia clearance occurs before death of adult worms.

On our case, doxycycline was used successfully for Ehrlichia spp. and HE clearance after two treatment courses and one year of ivermectin every 15 days. The animal presented intermittent coughing episodes on the first treatment course, but no medical intervention was needed besides exercise restriction. It is noteworthy the persistent thrombocytopenia after detection and treatment of the comorbidity (Table 1). Low platelet count is reported in E. canis, D. immitis, and L. infantum infection and several mechanisms are described such as immune mediated destruction, dysfunction, splenic sequestration via complement biding and vasculitis $[7,12,20,27]$. The exact mechanism that occurred on this report was not investigated. Regardless of the low platelet count, as the dog became clinically healthy and negative on all tests used, therapeutic intervention with ivermectin or allopurinol were not supported after one year.

Our report shows the successful management of one dog with CanL, CE and HE comorbidity. This success was possible due to early detection and good therapeutic choice. The authors also reinforce the importance of performing differential diagnosis for CVBD in endemic areas, regardless of one infection detected, other pathogens may infect the same animal, and treatment success will depend on commitment of veterinary practitioner to find these pathogens. Additionally, prevent vectors on an infected/suspected animal is ethically fundamental to avoid zoonotic transmission. 
A. Leal-Lima, T.C. Ferreira, T.M.V. Ferreira, P.C. Coelho \& D.C.S. Nunes-Pinheiro. 2021. Successful Treatment and Management of Canine Ehrlichiosis-Leishmaniosis-Heartworm Comorbidity.

\section{MANUFACTURERS}

${ }^{1}$ Bio-Manguinhos - Fiocruz. Rio de Janeiro, RJ, Brazil.

${ }^{2}$ Agener União Saúde Animal. São Paulo, SP, Brazil.

${ }^{3}$ Sanofi Medley Farmacêutica Ltda. Suzano, SP, Brazil.

${ }^{4}$ EMS Pharma. Hortolândia, SP, Brazil.

${ }^{5}$ MSD Saúde Animal. São Paulo, SP, Brazil.

${ }^{6}$ Winner Horse. Porto Feliz, SP, Brazil.
${ }^{7}$ Vetnil Ind. e Com. de Produtos Veterinários Ltda. Louveira, SP, Brazil.

${ }^{8}$ Ceva Saúde Animal Ltda. Paulínia, SP, Brazil.

Declaration of interest. The authors declare no conflicts of interest. The authors were responsible for the content and writing of the paper.

\section{REFERENCES}

1 Amante J.F.A.A., Santos A.R., Santos B.M., Mantovan K.B., Joaquim S.F., Latosinski G.S., Menozzi B.D., Hataka A., Lucheis S.B., Venturini J. \& Langoni H. 2020. Marbofloxacin induces leishmanicidal activity and less inflammatory response in Leishmania chagasi infected macrophages. Veterinária e Zootecnia. 27: 1-11.

2 Baneth G., Bourdeau P., Bourdoiseau G., Bowman D., Breitschwerdt E., Capelli G., Cardoso L., Dantas-Torres F., Day M., Dedet J.P., Dobler G., Ferrer L., Irwin P., Kempf V., Kohn B., Lappin M., Little S., Maggi R., Mirá G., Naucke T., Oliva G., Otranto D., Penzhorn B., Pfeffer M., Roura X., Sainz A., Shaw S., Shin S., Solano-Gallego L., Straubinger R., Traub R., Trees A., Truyen U., Demonceau T., Fitzgerald R., Gatti D., Hostetler J., Kilmer B., Krieger K., Mencke N., Mendão C., Mottier L., Pachnicke S., Rees B., Siebert S., Stanneck D., Tarancán Mingote M., Von Simson C. \& Weston S. 2012. Vector-borne diseases - Constant challenge for practicing veterinarians: Recommendations from the CVBD World Forum. Parasites and Vectors. 5(1): 2-4.

3 Bazzocchi C., Mortarino M., Grandi G., Kramer L.H., Genchi C., Bandi C., Genchi M., Sacchi L. \& McCall J.W. 2008. Combined ivermectin and doxycycline treatment has microfilaricidal and adulticidal activity against Dirofilaria immitis in experimentally infected dogs. International Journal for Parasitology. 38(12): 1401-1410.

4 Bendas A.J.R., Mendes-de-Almeida F., Guerrero J. \& Labarthe N. 2017. Atualização sobre a epidemiologia de Dirofilaria immitis na América do sul e no México: Revisão de literatura. Brazilian Journal of Veterinary Research and Animal Science. 54(4): 319-329.

5 Bowman D.D. \& Atkins C.E. 2009. Heartworm Biology, Treatment, and Control. Veterinary Clinics of North America - Small Animal Practice. 39(6): 1127-1158.

6 Brasileish. 2018. Diretrizes para o diagnóstico, estadiamento, tratamento e prevenção da Leishmaniose Canina. Disponível em: https://www.brasileish.com.br/assets/files/DIRETRIZES_Brasileish_2.pdf

7 Cortese L., Pelagalli A., Piantedosi D., Mastellone V., Manco A., Lombardi P., Ciaramella P. \& Avallone L. 2006. Platelet aggregation and haemostatic response in dogs naturally co-infected by Leishmania infantum and Ehrlichia canis. Journal of Veterinary Medicine Series A: Physiology Pathology Clinical Medicine. 53(10): 546-548.

8 Da Silva A.C.T., Santos J.R.S., Silva R.M.N., Santana V.L., Martins F.S.M., Falcão B.M.R., Tanikawa A., Almeida T.M., Vaz A.F.M. \& Souza A.P. 2021. Prednisolone associated with doxycycline on the hematological parameters and serum proteinogram of dogs with ehrlichiosis. Ciência Rural. 51(3): 1-9.

9 Dantas-Torres F. \& Otranto D. 2020. Overview on Dirofilaria immitis in the Americas, with notes on other filarial worms infecting dogs. Veterinary Parasitology. 282: 109113. DOI: 10.1016/j.vetpar.2020.109113.

10 De Tommasi A.S. Otranto D., Dantas-Torres F., Capelli G., Breitschwerdt E.B. \& Caprariis D. 2013. Are vector-borne pathogen co-infections complicating the clinical presentation in dogs? Parasites \& Vectors. 6(1): 97. DOI: 10.1186/1756-3305-6-97

11 Farca A.M., Miniscalco B., Badino P., Odore R., Monticelli P., Trisciuoglio A. \& Ferroglio E. 2012. Canine leishmaniosis: In vitro efficacy of miltefosine and marbofloxacin alone or in combination with allopurinol against clinical strains of Leishmania infantum. Parasitology Research. 110(6): 2509-2513.

12 Harrus S., Waner T., Weiss D.J., Keysary A. \& Bark H. 1996. Kinetics of serum antiplatelet antibodies in experimental acute canine ehrlichiosis. Veterinary Immunology and Immunopathology. 51(1-2): 13-20.

13 Lima A.L., Santos G.J.L., Roatt B.M., Reis A.B., Freitas J.C.C. \& Nunes-Pinheiro D.C.S. 2015. Serum TNF- $\alpha$ and IL-10 in Ehrlichia spp. Naturally Infected Dogs. Acta Scientiae Veterinariae. 43: 1322. 7p.

14 Lina T.T., Luo T., Velayutham T., Das S. \& McBride J.W. 2017. Ehrlichia Activation of Wnt-PI3K-mTOR Signaling Inhibits Autolysosome Generation and Autophagic Destruction by the Mononuclear Phagocyte. Infection and Immunity. 85(12): 1-17. 
A. Leal-Lima, T.C. Ferreira, T.M.V. Ferreira, P.C. Coelho \& D.C.S. Nunes-Pinheiro. 2021. Successful Treatment and

15 Magalhães-Junior J.T., Mota T.F., Porfirio-Passos G., Larangeira D.F., Franke C.R. \& Barrouin-Melo S.M. 2016. Xenodiagnosis on dogs with visceral leishmaniasis: Canine and sand fly aspects related to the parasite transmission. Veterinary Parasitology. 223: 120-126.

16 McCall J.W., Kramer L., Genchi C., Guerrero J., Dzimianski M.T., Mansour A., McCall S.D. \& Carson B. 2014. Effects of doxycycline on heartworm embryogenesis, transmission, circulating microfilaria, and adult worms in microfilaremic dogs. Veterinary Parasitology. 206(1-2): 5-13.

17 Morchón R., López-Belmonte J., Bazzocchi C., Grandi G., Kramer L. \& Simón F. 2007. Dogs with patent Dirofilaria immitis infection have higher expression of circulating IL-4, IL-10 and iNOS mRNA than those with occult infection. Veterinary Immunology and Immunopathology. 115(1-2): 184-188.

18 Mylonakis M.E., Harrus S. \& Breitschwerdt E.B. 2019. An update on the treatment of canine monocytic ehrlichiosis (Ehrlichia canis). Veterinary Journal. 246: 45-53.

19 Mylonakis M.E., Koutinas A.F., Breitschwerdt E.B., Hegarty B.C., Billinis C.D., Leontides L.S. \& Kontos V.S. 2004. Chronic Canine Ehrlichiosis (Ehrlichia canis): A Retrospective Study of 19 Natural Cases. Journal of the American Animal Hospital Association. 40(3): 174-184.

20 Nicolai L., Gaertner F. \& Massberg S. 2019. Platelets in Host Defense: Experimental and Clinical Insights. Trends in Immunology. 40(10): 922-938.

21 Passeri B., Vismarra A., Cricri G., Bazzocchi C., Kramer L. \& Bacci C. 2014. The adulticide effect of a combination of doxycycline and ivermectin in Dirofilaria immitis-experimentally infected dogs is associated with reduction in local T regulatory cell populations. Veterinary Parasitology. 205(1-2): 208-210.

22 Pineda C., Aguilera-Tejero E., Morales M.C., Belinchon-Lorenzo S., Gomez-Nieto L.C., Garcia P., Martinez-Moreno J.M., Rodriguez-Ortiz M.E. \& Lopez I. 2017. Treatment of canine leishmaniasis with marbofloxacin in dogs with renal disease. PLoS ONE. 12(10): 1-17.

23 Roatt B.M., Aguiar-Soares R.D. de O., Coura-Vital W., Ker H.G., Moreira N. das D., Vitoriano-Souza J., Giunchetti R.C., Carneiro C.M. \& Reis A.B. 2014. Immunotherapy and immunochemotherapy in visceral leishmaniasis: Promising treatments for this neglected disease. Frontiers in Immunology. 5: 272. DOI: 10.3389/fimmu.2014.00272

24 Roatt B.M., Aguiar-Soares R.D.O., Reis L.E.S., Cardoso J.M.O., Mathias F.A.S., Brito R.C.F., Silva S.M., Gontijo N.D.F., Ferreira S.A., Valenzuela J.G., Corrêa-Oliveira R., Giunchetti R.C. \& Reis A.B. 2017. A vaccine therapy for canine visceral leishmaniasis promoted significant improvement of clinical and immune status with reduction in parasite burden. Frontiers in Immunology. 8: 217. DOI: 10.3389/fimmu.2017.00217

25 Rougier S., Hasseine L., Delaunay P., Michel G. \& Marty P. 2012. One-year clinical and parasitological follow-up of dogs treated with marbofloxacin for canine leishmaniosis. Veterinary Parasitology. 186(3-4): 245-253.

26 Sabaté D., Llinás J., Homedes J., Sust M. \& Ferrer L. 2014. A single-centre, open-label, controlled, randomized clinical trial to assess the preventive efficacy of a domperidone-based treatment programme against clinical canine leishmaniasis in a high prevalence area. Preventive Veterinary Medicine. 115(1-2): 56-63.

27 Silveira N.S.D., Mendes E.M., Pereira M.L., Tavela A.D.O., Patricia A., Veiga M. \& Zimermann F.C. 2021. Leishmaniose visceral em cães. Acta Scientiae Veterinariae. 49: 610. 12p.

28 Solano-Gallego L., Miró G., Koutinas A., Cardoso L., Pennisi M.G., Ferrer L., Bourdeau P., Oliva G., Baneth G. \& The LeishVet Group. 2011. LeishVet guidelines for the practical management of canine leishmaniosis. Parasites \& Vectors. 4(1): 86. DOI: 10.1186/1756-3305-4-86

29 Todorovic S. \& McKay T. 2020. Potential mosquito (Diptera: Culicidae) vectors of Dirofilaria immitis from residential entryways in Northeast Arkansas. Veterinary Parasitology. 282: 109105. DOI: 10.1016/j.vetpar.2020.109105

30 Toepp A., Larson M., Wilson G., Grinnage-Pulley T., Bennett C., Leal-Lima A., Anderson B., Parrish M., Anderson M., Fowler H., Hinman J., Kontowicz E., Jefferies J., Beeman M., Buch J., Saucier J., Tyrrell P., Gharpure R., Cotter C. \& Petersen C. 2018. Randomized, controlled, double-blinded field trial to assess Leishmania vaccine effectiveness as immunotherapy for canine leishmaniosis. Vaccine. 36(43): 6433-6441.

31 Toepp A.J., Monteiro G.R.G., Coutinho J.F.V., Lima A.L., Larson M., Wilson G., Grinnage-Pulley T., Bennett C., Mahachi K., Anderson B., Ozanne M. V., Anderson M., Fowler H., Parrish M., Willardson K., Saucier J., Tyrell P., Palmer Z., Buch J., Chandrashekar R., Brown G.D., Oleson J.J., Jeronimo S.M.B. \& Petersen C.A. 2019. Comorbid infections induce progression of visceral leishmaniasis. Parasites \& Vectors. 12(1): 54. DOI: 10.1186/ s13071-019-3312-3 
A. Leal-Lima, T.C. Ferreira, T.M.V. Ferreira, P.C. Coelho \& D.C.S. Nunes-Pinheiro. 2021. Successful Treatment and Management of Canine Ehrlichiosis-Leishmaniosis-Heartworm Comorbidity.

Acta Scientiae Veterinariae. 49(Suppl 1): 687.

32 Toepp A.J. \& Petersen C.A. 2020. The balancing act: Immunology of leishmaniosis. Research in Veterinary Science. 130: 19-25. DOI: 10.1016/j.rvsc.2020.02.004

33 Travi B.L. \& Miró G. 2018. Use of domperidone in canine visceral leishmaniasis: gaps in veterinary knowledge and epidemiological implications. Memórias do Instituto Oswaldo Cruz. 113(11): e180301.

34 Villaescusa A., García-Sancho M., Rodríguez-Franco F., Tesouro M.Á. \& Sainz Á. 2015. Effects of doxycycline on haematology, blood chemistry and peripheral blood lymphocyte subsets of healthy dogs and dogs naturally infected with Ehrlichia canis. The Veterinary Journal. 204(3): 263-268. 